\title{
TINJAUAN KETERAMPILAN TEKNIK DASAR KLUB BOLABASKET PUTRA SEKOLAH MENENGAH ATAS PEMBANGUNAN LABORATORIUM UNIVERSITAS NEGERI PADANG
}

\section{Oleh \\ Nirwandi ${ }^{1)}$ \\ Fakultas IImu Keolahragaan Universitas Negeri Padang}

Tujuan penelitian ini berguna nantinya untuk memotivasi atlet agar memperbaiki teknik mereka ke arah yang lebih baik. Penelitian ini menggunakan metode deskriptif. Populasi dalam penelitian ini adalah klub bolabasket putra Sekolah Menengah Atas Pembangunan Laboratorium UNP yang berjumlah 15 pemain. Teknik pengambilan sampel dalam penelitian ini menggunakan teknik total sampling. Instrumen penelitian ini menggunakan rangkaian tes tingkat teknik dasar bermain bolabasket yang meliputi, kemampuan shooting, dribbling dan passing.Analisis data dalam penelitian ini menggunakan metode analisis statistik deskriptif. Berdasarkan analisis statistik deskriptif, didapatkan hasil penelitian sebagai berikut, kemampuan memasukkan bola ke ring lawan (shooting) terbanyak berada pada kategori kurang dengan nilai T- Score 50-59 dan persentase $40 \%$. Kemampuan menggiring bola (dribbling) tim bolabasket berada pada kategori baik dengan nilai T-Score $65-69$ dan persentase $33,33 \%$. Kemampuan mengoper bola (passing) tim bolabasket berada pada kategori sedang dengan nilai T-Score 60-64 dan persentase $33,33 \%$.

Kata Kunci: Teknik Dasar Bolabasket

\section{Pendahuluan}

Perkembangan ilmu pengetahuan dan teknologi pada saat sekarang ini telah membawa kemajuan dalam segala bidang. Salah satunya pada bidang olahraga, khususnya olahraga bolabasket. Permainan bolabasket merupakan salah satu dari olahraga permainan yang banyak digemari oleh berbagai lapisan masyarakat, karena permainan bolabasket dapat dilakukan oleh anak-anak, para remaja, dan juga orang dewasa.

$\mathrm{Di}$ Indonesia permainan bolabasket berkembang dengan cepat. Perkembangannya dimulai setelah proklamasi kemerdekaan, dimulai dari daerah di sekitar Semarang. Sebelum kemerdekaan, permainan ini sudah dimainkan di sekolah-sekolah keturunan Tionghoa, namun belum melibatkan kepentingan seluruh masyarakat. Dan setelah proklamasi kemerdekaan Indonesia, permainan ini baru dimainkan di semua sekolah yang ada, bukan hanya sekolah keturunan Tionghowa saja. Sehingga pada pada tahun 1948 permainan bolabasket diperlombakan untuk pertama kalinya di PON I di Solo. Pada awal masa kemardekaan tersebut bangsa Indonesia masih menghadapi ancaman dari pihak penjajahan Belanda yang berhasil 
merampas beberapa bagian wilayah Negara kesatuan republik Indonesia yang telah di proklamirkan.

Adnan Fardi (1999: 18) mengatakan bahwa "pada tanggal 23 oktober 1951, dibentuklah organisasi PERBASI (Persatuan Basketball seluruh Indonesia) dan kemudian pada tahun 1955 persatuan basketball seluruh Indonesia berubah menjadi persatuan bolabasket seluruh Indonesia. Untuk melihatkan kinerjanya, maka PERBASI mengadakan konferensi se-Jawa Bandung, dimana hasil konferensi tersebut PERBASI menjadikan dirinya sebagai induk organisasi cabang bolabasket di Indonesia.

Sampai pada saat sekarang ini, PERBASI masih melihatkan kinerjanya. Dimana perkembangan bolabasket Indonesia cukup menjanjikan di tingkat nasional maupun internasional. Hal ini dapat dilihat dari adanya kompetensi bergengsi yang bergulir di tingkat nasional seperti, LIBAMA atau Liga Basket Mahasiswa, IBL atau Indonesia Basketball League, dan masih banyak lagi kompetisikompetisi yang bergulir di Indonesia pada saat sekarang ini. Bukan hanya di level profesional saja kompetisi bolabasket diadakan, akan tetapi pada tingkat pelajarpun masih banyak diadakan kompetisi-kompetisi bolabasket. Sehingga pada saat sekarang ini para pelatih olahraga bolabasket berlomba-lomba untuk melatih dan mendidik Club nya sehingga Club nya menjadi Klub yang berprestasi dan menjadi juara pada kompetisi-kompetisi yang diikutinya.

Permainan bolabasket, merupakan pemainan yang banyak menggunakan keterampilan gerak. Sehingga jika seorang pemain memiliki suatu keterampilan gerak yang bagus maka gerakan yang ia lakukan akan terlihat indah. Hal itu tidak terlepas dari teknik dasar permainan bolabasket. Adapun teknik-teknik dasar yang harus dimiliki oleh para permainan bolabasket mencakup foot work (gerakan kaki), Shooting (menembak), passing (operan), menangkap, melakukan drible, gerakan dengan bola, gerakan tanpa bola, dan gerakan bertahan. Dari semua gerakan-gerakan yang ada diatas, dapat dirangkai untuk menjadi sebuah rangkaian gerakan dalam permainan bolabasket.

\section{METODE}

\section{A. Jenis Penelitian}

Jenis penelitian ini adalah penelitian deskriptif yaitu salah satu jenis penelitian yang mendeskripsikan secara sistematis, aktual dan akurat mengenai fakta-fakta populasi tertentu atau mencoba menggambarkan fenomena secara detail. (Subana. M, tahun 2001:8).

\section{B. Populasi dan Sampel}

\section{a. Populasi}

Populasi dalam penelitian ini adalah seluruh Klub putra basket di Sekolah Menengah Atas Pembangunan Laboratorium Universitas Negeri Padang yang berjumlah 15 orang. 


\section{b. Sampel}

Sampel adalah sebagian atau wakil populasi yang diteliti (Arikunto, 2002:109). Berdasarkan populasi di atas, pengambilan sampel dilakukan dengan teknik "Total sampling". Sampel yang diambil dalam penelitian ini keseluruhan populasi Klub putra Sekolah Menengah Atas Pembangunan Laboratorium berjumlah 15

C. Instrumen Penelitian

1. Memantulkan (passing bola/ chess pass) ke dinding

Tujuan : Untuk mengukur daya tahan dan daya ledak kekuatan otot lengan

Alat-alat : Bolabasket, sasaran pada tembok, stopwatch, blangko dan alat tulis

Petugas : Pengambilan waktu dan pencatat

Pelaksanaan : Sebuah sasaran dibuat di dinding tembok bagaimana pada gambar. Testee berdiri pada garis batas dengan bola ditangan,Pada aba-aba pelaksanaan testee melemparkan bola ke daerah sasaran di dinding dengan lemparan chest pas,Bola yang memantul dari tembok ditangkap dan dipantulkan kembali sebanyak-banyaknya selama 15 detik. Pantulan sah apabila bola memantul pada garis dulu dalam daerah sasaran dan dilakukan dari belakang garis batas. Memantulkan bola tidak terkuasai dan bola jauh dari garis batas, segera ambil dan lanjutkan pelaksanaan tes.

Penilaian

Hitunglah jumlah pantulan yang sah selama 15 detik.

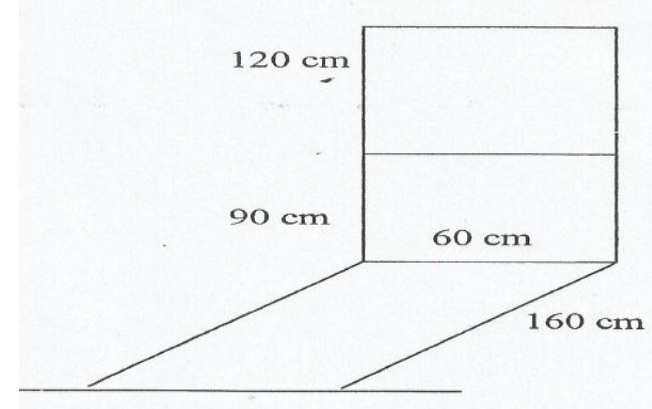

Gambar 13. Daerah sasaran pada tes passing, Arsil (2009.111)

\section{Menggiring Bola}

Tujuan :Tes ini untuk mengukur kecepatan menggiring bola maupun kelincahan merubah arah

Alat-alat :Bola, stopwatch, pluit, blangko dan alat tulis

Petugas :Starter merangkap pengambil waktu dan pencatat

Pelaksanaan :Pada aba-aba 'siap' testee berdiri dibelakang garis star, letakkan bola ditengahtengah garis start. Setelah aba-aba 'ya' testee segera mengambil bola dan menggiringnya sesuai dengan arah atau 


lintasan yang ditentukan,
sampai kembali dan
melewati garis finish.
Menggiring bola boleh
berganti tangan asal
sesuai dengan peraturan
permainan bolabasket.
Bola tetap digiring saat
melalui garis finish.
Apabila saat menggiring
bola mantul jauh, ulangi
test segera. Bila saat
menggiring bola tidak
memantul atau tidak
dapat dikuasai, bola
boleh di pegang dan
segera digiring kembali.
: Kecepatan menggiring
bola dihitung dari saat
aba-aba ya' sampai
testee melampaui garis
finish. Kecepatan
menggiring dihitung
sampai 0.1 detik.

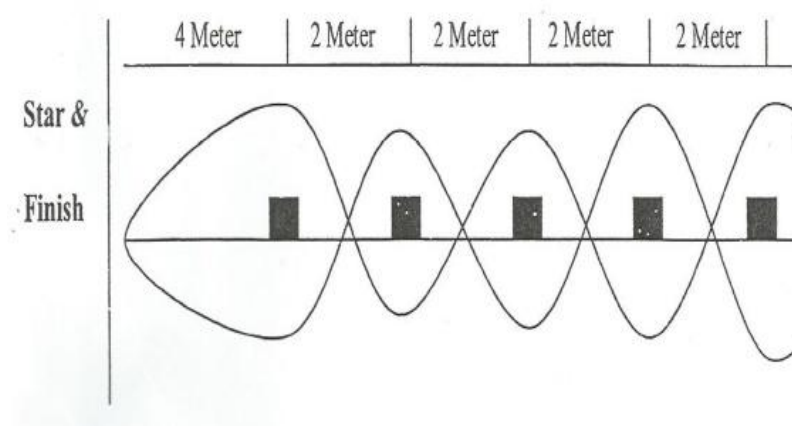

Gambar 14. Gambar lintasan pada tes dribbling

3. Menembak underbasket (shooting) selama satu menit

Tujuan : Tes ini untuk mengukur ketepatan dan ketelitian menembak ke dalam ring basket

\begin{abstract}
Alat-alat : Bolabasket, stopwatch, ring, pluit, blangko dan alat tulis

Petugas : Pengambil waktu

Pelaksanaan : Pada aba-aba 'siap' testee berdiri bebas dibawah ring dengan bola ditangan. Setelah aba-aba 'ya' testee segera menembak bola ke ring sebanyak mungkin selama satu menit. Apabila bola mental jauh atau tidak terkuasai lagi, segera ambil bola dan lanjutkan tes.

Penilaian: Setiap bola yang masuk ke ring mendapatkan nilai satu. Apabila waktu aba-aba 'stop' telah diberikan sedangkan bola sudah lepas dari tangan dan bola masuk tetap mendapatkan nilai.
\end{abstract}

\section{Teknik Analisa Data}

Penelitian ini menggunakan teknik analisis dalam mengolah data dengan menggunakan rumus presentase dan dikonversi ke norma tes keterampilan teknik dasar bolabasket.

Hasil penelitian akan ditransformasikan melalui T-Score lalu untuk menentukan keterampilan secara umum jumlah keseluruhan nilai shooting, passing dan dribbling akan dikalkulasikan sesuai norma. 


\section{PEMBAHASAN}

\section{Shooting}

Berdasarkan pada tabel distribusi frekuensi, maka diperoleh hasil bahwa dari 15 orang sampel, 2 orang (13,33\%) memiliki kemampuan shooting baik dengan T- Score 70-79, 5 orang $(33,33 \%)$ memiliki kemampuan shooting sedang dengan T-Score 60-69, 6 orang $(40 \%)$ memiliki kemampuan shooting kurang dengan T-Score 50-59, dan 2 oranf (13.33\%) memiliki kemampuan shooting kurang sekali dengan T- Score 4049

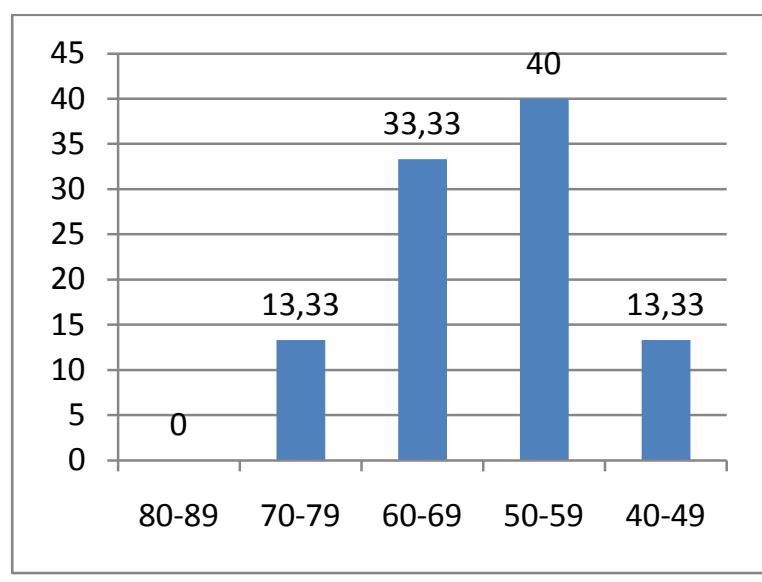

Rata-rata tingkat kemampuan shooting tim bolabasket putra Sekolah Menengah Aatas Pembangunan Laboratorium Universitas Negeri Padang yang dijadikan sampel dalam penelitian ini, terbanyak berada pada T-Score 50 - 59. Hal ini tentunya belum cukup optimal dalam pencapaian prestasi, maka harus ditingkatkan dengan adanya peningkatan terhadap proses latihan. Menurut Tara vanderveel dalam buku
Women is Basketball Drill Book (tahun 2007 ) cara latihan yang harus dilakukan untuk meninggkatkan kemampuan shooting dengan cara meningkankan intensitas latihan yang biasanya satu minggu, ditingkatkan dengan waktu selama dua minggu, dengan latihan shooting dititik-titik yang telah ditentukan dengan waktu yang telah ditentukan .

\section{Dribbling}

Berdasarkan pada tabel distribusi frekuensi diatas, maka diperoleh hasil bahwa dari 15 orang sampel, 2 orang $(13,33 \%)$ memiliki kemampuan dribbling baik sekali dengan T- Score 70-74, 5 orang $(33,33 \%) \quad$ memiliki kemampuan dribbling baik dengan T- Score 65-69, 2 orang $(13,33 \%)$ memiliki kemampuan dribbling sedang dengan T- Score 6064,3 orang $(20 \%)$ memiliki kemampuan dribbling kurang dengan T- Score 5559 , dan 3 orang (20\%) memiliki kemampuan dribbling kurang sekali dengan T-Score 50-54.

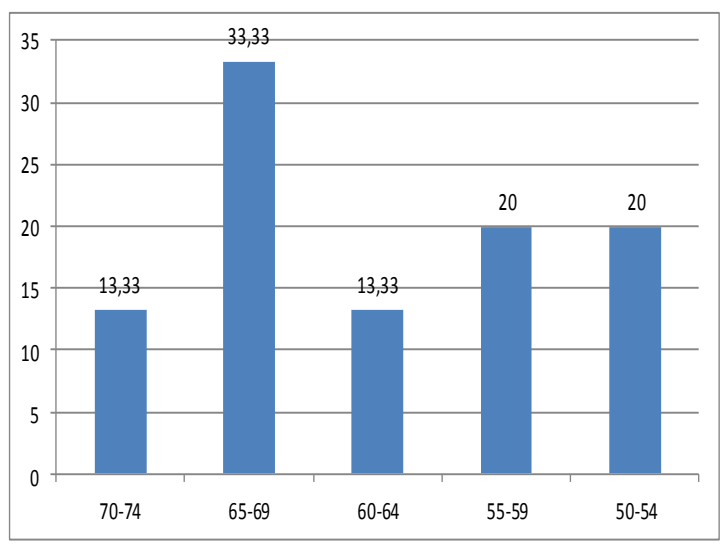

Rata-rata tingkat kemampuan dribbling tim bolabasket putra Sekolah Menengah Atas 
Pembangunan Laboratorium Universitas Negeri Padang yang dijadikan sampel dalam penelitian ini, terbanyak berada pada T-Score 65 - 69. Hal ini tentunya tidak menguntungkan bagi siswa itu sendiri dalam pertandingan. Walaupun kemampuan teknik dasar yang lainnya bagus tetapi tidak didukung oleh kemampuan dribbling yang bagus akan sangat mempengaruhi pola permainan tim bolabasket Sekolah Menengah Atas Pembangunan Laboratorium Universitas Negeri Padang. Oleh sebab itu, perlu ditingkatkan dengan latihan dribbling yang kontinu dan terarah. Menurut Tara vanderveel dalam buku Women is Basketball Drill Book ( tahun 2007 ), yang dimana dapat dilakukan dengan cara mengulang latihan dribbling dengan cara peningkatan latihan yang dimana biasanya hanya melakukan slow dribbling dang meningkatkan latihan dengan melakukan speet driblling.

\section{Passing}

Berdasarkan pada tabel distribusi frekuensi diatas, maka diperoleh hasil bahwa dari 15 orang sampel, 3 orang (20\%) memiliki kemampuan passing baik sekali dengan T-Score 70-74, 2 orang (13,33\%) memiliki kemampuan passing baik dengan T- Score 65-69, 5 orang (33,33\%) memiliki kemampuan passing sedang dengan T- Score 60-64, 2 orang (13,33\%) memiliki kemampuan passing kurang dengan T- Score 55-59, dan 3 orang $(20 \%)$ memiliki kemampuan passing kurang sekali dengan TScore 50-54.

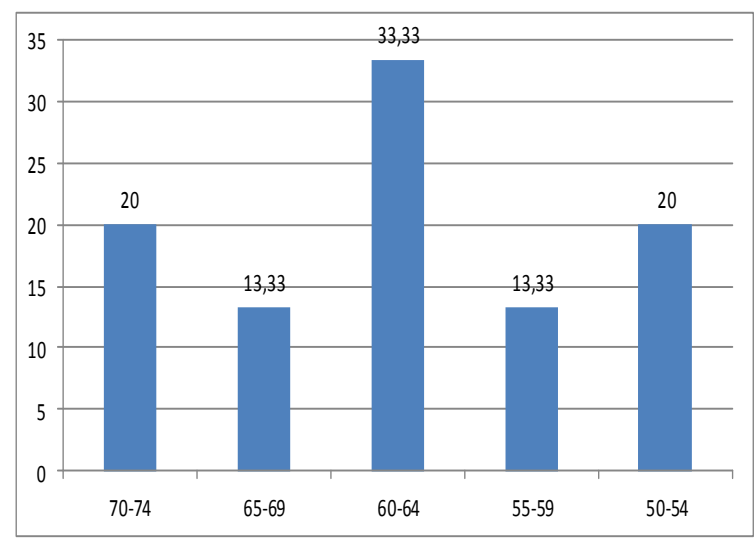

Rata-rata kemampuan passing tim bolabasket putra Seekolah Menengah Aatas Pembangunan Laboratorium Universitas Negeri Padang yang dijadikan sampel di dalam penelitian ini, terbanyak berada pada T-Score 60 - 64. Hal ini tentunya belum optimal dalam pencapaian prestasi oleh sebab itu harus ditingkatkan dengan adanya peningkatan terhadap proses latihan. Menurut Tara vandervee/ dalam buku Women is Basketball Drill Book (tahun 2007), peningkatan latihan dapat dilakukan dengan cara latihan Drill yang dilakukan dengan cara berpasangan dan juga dengan cara berkelompok.

\section{Keterampilan Teknik Dasar Bolabasket}

Berdasarkan pada tabel distribusi kategori diatas, maka diperoleh hasil bahwa dari 15 sampel, 5 orang $(33,33 \%)$ memiliki kemampuan teknik dasar bolabasket dengan kategori baik, 7 orang $(46,67 \%)$ memiliki kemampuan teknik dasar bolabasket dengan 
kategori cukup, dan 3 orang (20\%) memiliki kemampuan teknik dasar bolabasket dengan kategori sedang.

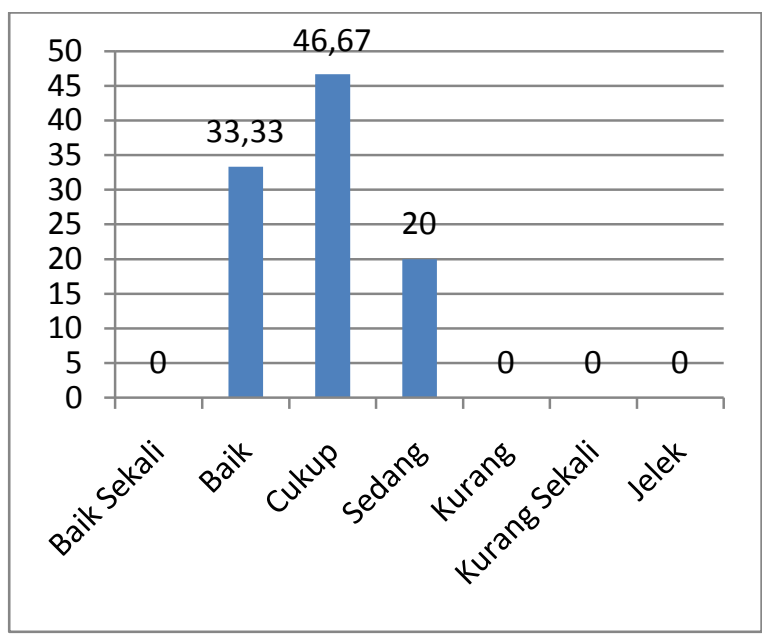

Setelah melakukan tes pada masing-masing teknik dasar pada permainan bolabasket, maka dapat ditarik kesimpulan tentang kemampuan teknik dasar bolabasket tim bolabasket putra Sekolah Menengah Atas Pembangunan Laboratorium Universitas Negeri Padang. Ratarata kemampuan teknik dasar bolabasket tim bolabasket putra Sekolah Menengah Atas Pembangunan Laboratorium Universitas Negeri Padang yang dijadikan sampel di dalam penelitian ini terbanyak berada pada kategori cukup dengan TScore 165-192. Hal ini tentunya belum optimal dalam pencapaian prestasi oleh sebab itu harus ditingkatkan dengan adanya peningkatan terhadap proses latihan.

Dengan demikian, dapat
disimpulkan bahwa dalam
bolabasket banyak hal yang
terjadi dilapangan, seperti akan

terjadi aksi penyerangan dan pertahanan, dan semua itu membutuhkan keterampilan teknik bolabasket yang baik agar dapat mengatasi permasalahanpermasalahan yang terjadi dilapangan. Namun, kemampuan teknik dasar tim bolabasket putra Sekolah Menengah Atas Pembangunan Laboratorium Universitas Negeri Padang yang dimiliki sekarang masih berada pada kategori sedang, sehingga perlu ditingkatkan dengan melakukan proses latihan yang terencana dan sistematis serta dilakukan secara kontiniu dan berkesinambungan untuk menghasilkan kemampuan teknik dasar yang lebih baik lagi.

\section{DAFTAR RUJUKAN}

Arsil. (1999). Evaluasi Pendidikan Jasmani dan Olahraga. Padang: FIK UNP.

Danny Kosasih. (2008). Fundamental Basket Ball. Semarang : Karangturi

Fardi, Adnan (1999). Bola Basket Dasar. Padang:UNP

PP. PERBASI.(2012). Pengaturan Permainan Bola Basket. Jakarta : PERBASI.

Imam Sodikoen. (1991). Pembinaan Prestasi Bola Basket di $P G S D$. Jakarta: P2TK Dirjen Dikti Dikbud.

Imam Sodikoen. (1992). Olahraga Pilihan Bola Basket. Padang : FPOK IKIP Padang. 
Madri, S. (2012). The Basic Learning Basket Ball Technique. Padang : Sukabina Press

Mawardi Efendi. (2007). Buku Pedoman Akademik. Padang : FIK UNP Mochamad Arifin. (1994). Pendidikan Jasmani dan Kesehatan. Surabaya : Diktat=

Suharsimi Arikunto. (2002). "Manajemen Penelitian". Jakarta : Rineka Cipta

Suharsimi Arikunto.(2010). Prsedur Penelitian.Jakarta : PT Rineka Cipta.

Rusdiaman. (2014). Survey Teknik Dasar Permainan. http://amankrusdiaman.blogs pot.com/2014/03/surveiteknik-dasar-permainan.html. Diakses Pada 2 Desember 2015

Witarsyah. (2005). Bola Basket Pendalaman. Padang : FIK UNP.

Yanto Kusyanto. (1994). Pendidikan Jasmani dan Kesehatan. Bandung : Ganesa 